\title{
Saturated fat in the diet of Spanish children: relationship with anthropometric, alimentary, nutritional and lipid profiles
}

\author{
MA Royo-Bordonada 1,* , C Garcés², L Gorgojo', JM Martín-Moreno 1,3 , MA Lasunción ${ }^{4}$, \\ F Rodríguez-Artalejo ${ }^{3}, \mathrm{O}$ Fernández ${ }^{5}$ and $M$ de Oya ${ }^{2}$ on behalf of the Investigators of the \\ Four Provinces Study† \\ ${ }^{1}$ Instituto de Salud Carlos III, Ministerio de Sanidad y Consumo, Paseo del Prado 18-20, E-28071 Madrid, Spain: \\ ${ }^{2}$ Laboratorio de Lípidos, Fundación Jiménez Díaz, Madrid, Spain: ${ }^{3}$ Departamento de Medicina Preventiva y Salud \\ Pública, Universidad Autónoma de Madrid, Madrid, Spain: ${ }^{4}$ Departamento de Bioquímica y Biología Molecular, \\ Universidad de Alcalá de Henares, Madrid, Spain: ${ }^{5}$ Servicio de Medicina Interna, Complexo Hospitalario de \\ Ourense, Ourense, Spain
}

Submitted 13 July 2004: Accepted 23 August 2005

\begin{abstract}
Objective: To compare the anthropometric, alimentary, nutritional and lipid profiles and global diet quality of Spanish children according to saturated fat intake.

Design: This was a cross-sectional study. Food data were collected using a foodfrequency questionnaire.

Subjects and methods: The sample included 1112 children of both sexes, aged between 6 and 7 years, selected by means of random cluster sampling in schools. The plasma lipid profile included measurements of low-density lipoprotein cholesterol (LDL-C), high-density lipoprotein cholesterol (HDL-C), triglycerides, apolipoprotein A1 (apoA1) and apolipoprotein B (apoB). Global diet quality was evaluated by the Dietary Variety Index (DVI) and the Healthy Eating Index (HEI).

Results: Energy intake, DVI and HEI of children from the lower quartile of saturated fat intake (LL) were higher $(P<001)$ than in the remaining children (UL). However, there were no significant differences in average height or weight between groups. The UL children had lower intakes of meat, fish, vegetables, fruits and olive oil and a higher intake of dairy products $(P<0.001)$. The intakes of fibre, vitamins $\mathrm{C}, \mathrm{D}, \mathrm{B}_{6}, \mathrm{E}$ and folic acid were higher in the LL children, who had lower intakes of vitamin $\mathrm{A}$ and calcium. The ratios LDL-C/HDL-C and apoB/apoA1 were lower $(P=0.04)$ in the LL children (1.87 and 0.52, respectively) than in the UL children (2.02 and 0.54 , respectively).

Conclusions: The growth rate of children does not seem to be affected by the level of saturated fat intake. Furthermore, at the levels of intake observed in this study, diets with less saturated fat are associated with better alimentary, nutritional and plasma lipid profiles.
\end{abstract}

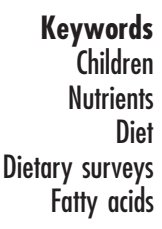

In adults, the consumption of saturated fatty acids (SFA) induces an increase in plasma low-density lipoprotein cholesterol (LDL-C) levels and is associated with greater cardiovascular risk. Furthermore, it seems that substituting this type of fat with unsaturated fatty acids is a more effective means of preventing cardiovascular risk factors than reducing total fat intake ${ }^{1}$. Consequently, while it is agreed that SFA intake should be less than 10\% of total energy intake, in the case of total fat intake the upper limit

†Investigators of the Four Provinces Study: M Benavente, R Rubio, JL del Barrio and A Studer (Fundación Jiménez Díaz), H Ortega (Hospital Ramón y Cajal, Madrid), J Fernández Pardo (Hospital de la Cruz Roja, Murcia), A Macías and A Mangas (Universidad de Cádiz). recommended by various societies and organisations ranges from 30 to $35 \%^{2-5}$.

The association between SFA and plasma cholesterol levels in children is similar to that observed for adults ${ }^{6}$. Nevertheless, the small magnitude of this association to doubts about its possible clinical significance for children $^{7-9}$. On the other hand, given the complexity of carrying out studies that evaluate the effectiveness of different diets in children to prevent them from developing atherosclerosis as adults, the possible relationship between saturated fat intake in children and later cardiovascular risk is based on indirect evidence. Nevertheless, the American Academy of and the negative results in some studies have given rise 
Pediatrics recommends, based on this evidence, that children aged 2 to 18 years keep intakes of saturated fatty acids and total fat below 10\% and 30\% of energy intake, respectively ${ }^{10}$. While the majority of experts recommend energy intake of SFA below 10\% of total intake in children aged 2 years and above, there is less agreement on restricting total fat intake in this population $^{11-14}$.

Although some intervention studies show that reducing fat intake in the child population does not negatively affect growth rate or nutritional intake ${ }^{15-17}$, these diets with less fat have been applied in controlled conditions and with intensive medical supervision. On the other hand, there is evidence that, in normal conditions, this type of diet can be associated with delayed growth-for-age and lower intakes of certain micronutrients ${ }^{18,19}$. In this context, studies that analyse the nutritional status of children with lower fat intake can provide additional relevant information about the safety of this type of diet.

The objectives of the present study, which analysed the diet of school-age children from four provinces with differing demographic and sociocultural characteristics, were to examine the diet quality and anthropometric, dietary, nutritional and lipid profiles of those children with lower saturated fat intake (lowest quintile of SFA intake) and to compare them with data from the remaining children.

\section{Material and methods}

\section{Study subjects}

We selected representative samples of schoolchildren, aged 6-7 years, in four regions in Spain (Cadiz, Madrid, Orense and Murcia) over the period 1998-1999. These regions were chosen mainly because of the large difference in cardiovascular mortality between them. More detailed information about the design of the study is available in previous publications ${ }^{20,21}$.

Children were selected by means of random cluster sampling in schools, and stratified by sex and type of school (i.e. public vs. private). Type of school was an indicator of socio-economic level. Sampling was carried out in two stages. In the first stage, schools were selected from lists supplied by the regional educational authorities. In the second stage, classrooms and pupils were selected. In each region six schools were selected. Approximately 50 children were invited to participate in each school. All children reported by parents to be suffering from metabolic, endocrine, liver or kidney disorders were excluded, to rule out any possible alteration in the values of the variables of interest.

The study protocol complied with Helsinki Declaration guidelines and Spanish statutory provisions governing clinical research on humans ${ }^{22}$, and was formally approved by the Clinical Research Ethics
Committee of the Jiménez Díaz Foundation in Madrid (Spain).

\section{Data collection and study variables}

The study was presented orally to the board of governors (Consejo Escolar) of each of the schools. Following this, a letter was circulated to the parents of all children invited to participate in the study, outlining the study goals and procedures, and securing their written authorisation. In addition, this same letter urged all parents to seek the necessary consent from their children.

\section{Food and nutritional data}

At each school, data were collected by a field team comprising a physician, a nurse and a group of persons purpose-trained in the use of a food-frequency questionnaire (FFQ), who conducted the survey and obtained the information from the children's mothers or the people responsible for their food.

The FFQ, initially developed for use on adults and previously validated in Spain by Martín-Moreno et al. ${ }^{23}$, was adapted for a primary-school population by amending and downscaling the list of foods and portions consumed, eliminating alcoholic beverages and including some foods frequently found in a child's diet (e.g. pizzas, hamburgers, etc.). These amendments were based on a recent, systematic, in-depth review of child-population food surveys in Spain ${ }^{24}$. The final version of the FFQ included a total of 77 food items grouped under 11 headings by affinity in nutrient content. For each food, the usual size of the serving eaten was defined (e.g. 1 cup of milk equivalent to $170 \mathrm{ml}$; a dish of lentils equivalent to $60 \mathrm{~g}$ dry weight) and the mean frequency of consumption of such servings over the previous year ascertained. The FFQ provided five consumption frequency ratings (never, annually, monthly, weekly and daily). Standard Spanish food composition tables were used to convert the foods into nutrient and total energy intakes for each of the subjects included in the study ${ }^{25,26}$.

\section{Anthropometric variables}

Measurements were taken with the children lightly dressed and barefoot. Height was measured to the last millimetre using a portable stadiometer, and weight was measured to the last $0.1 \mathrm{~kg}$ using a standardised electronic digital scale. From these measurements, body mass index (BMI; weight in kilograms divided by the square of the height in metres, $\mathrm{kg} \mathrm{m}^{-2}$ ) was then computed. The prevalence of overweight and obese children was calculated as the percentage of children exceeding BMI cut-off points proposed in a recent synthesis of international studies ${ }^{27}$.

\section{Biochemical data}

Fasting (12 h) venous blood samples were obtained by venepuncture into Vacutainer ${ }^{\circledR}$ tubes containing 
ethylenediamine- $N, N, N^{\prime}, N^{\prime}$-tetraacetic acid. Samples were kept on ice and sent to the study's central laboratory for analysis. Once centrifuged, the fractions were separated and frozen at $-70^{\circ} \mathrm{C}$. Cholesterol and triglycerides were measured enzymatically (Menarini Diagnostics, Italy) with an RA-1000 Autoanalyzer. The cholesterol bound to highdensity lipoproteins (HDL-C) was determined after precipitation of lipoproteins containing apolipoprotein $\mathrm{B}$ (apoB) with phosphowolframic acid and magnesium (Boehringer Mannheim, Germany). The cholesterol bound to low-density lipoproteins (LDL-C) was calculated using the Friedewald formula.

\section{Dietary variety and overall dietary quality indices}

A Dietary Variety Index (DVI) was calculated using the number of different types of foods (items of the questionnaire) eaten more than once a month ${ }^{28}$. Similar foods were grouped as one single item for their evaluation as a component of dietary variety ${ }^{29}$. For example, whole milk and 1\%-fat milk were grouped in the same item, as were roast, boiled or fried potatoes. Thus, the final number of items was 72 . Overall dietary quality was assessed using the Healthy Eating Index $(\mathrm{HEI})^{30-32}$. This index consists of 10 items: the first five measure food groups (cereals, vegetables, fruit, dairy products and meat); the following four measure nutrients (total lipid, saturated fat, cholesterol and sodium); and the last one analyses dietary variety. For each HEI item, a value is established for which the minimum score ( 0 points) is obtained and another for which the maximum score (10 points) is obtained; between these two values, the score is obtained on a proportional basis. The total score, which can range between 0 and 100, is obtained by adding up the individual scores for the 10 items; the higher the score, the better the diet quality. One of our objectives was to evaluate the nutritional quality of the diet of children with a lower saturated fat intake. Given that the HEI includes saturated fat, total lipid and cholesterol intakes, we removed these three components from its calculation before comparing global diet quality between the two groups (low and high saturated fat intake). Thus, we have tried to avoid distorting effects from the fact that components of the independent variable (saturated fat intake) form a part of the dependent variable (HEI).

\section{Statistical analysis}

A $t$-test analysis or the Wilcoxon ranges sum, depending whether the variable had a normal distribution or not, was used to compare the mean values between groups. The comparisons were also made, adjusting for region, type of school and total energy intake ${ }^{33}$, through analysis of covariance. Statistical analyses were performed using the Statistical Analysis System computer software package ${ }^{34}$.

\section{Results}

The response rate was $85 \%$, consistently in the four cities. The sample group was made up of 1112 individuals, 557 (50.1\%) boys and 555 (49.9\%) girls, with an average age of 6.7 years. Keeping in mind that only $0.4 \%$ of the children had SFA intake less than $10 \%$ of their total energy intake, the sample was divided into quintiles of SFA intake. The children in the lower quintile $(<14.5 \%$ energy intake from SFA) formed the reference group (lower SFA intake level: LL) and the rest of the children formed the comparative group (upper SFA intake level: UL). In the low SFA intake group the percentage of girls $(57.7 \%)$ was higher than that of boys (42.3\%). Nevertheless, with the exception of plasma lipid levels, for which the differences between groups were slightly more pronounced in girls, no important gender differences were observed. Similar findings were observed when the results were stratified by region and type of school (data not shown). Also the results did not vary significantly when adjusting for total energy intake. This is why the tables present the results of our analysis for all of the subjects without adjusting for energy intake.

Although average daily energy intake was $230 \mathrm{kcal}$ $(\sim 960 \mathrm{~kJ})$ greater in children from the LL group, no differences were found between the groups in terms of weight, height or BMI. The percentage of overweight and obese subjects was slightly higher in the LL group but this was not statistically significant. The DVI and HEI scores of the LL children were also higher than those of the UL children $(P<0.01$ and $P<0.001$, respectively) (Table 1 ).

Regarding food intake, the LL children presented lower intakes of dairy products, eggs and baked goods, although the differences were statistically significant only in the case

Table 1 Demographic and anthropometric characteristics according to percentage of energy from saturated fatty acids (SFA)

\begin{tabular}{|c|c|c|c|}
\hline & SFA & take & \\
\hline & Lower $(\leq 14.5)$ & Upper $(>14.5)$ & $P$-value \\
\hline$n$ & 222 & 890 & \\
\hline Gender (\%) & & & \\
\hline Boys & 42.3 & 52.0 & 0.01 \\
\hline Girls & 57.7 & 48.0 & 0.01 \\
\hline Age (years) & 6.8 & 6.7 & 0.36 \\
\hline Energy & & & \\
\hline$\left(\mathrm{kJ} \mathrm{day}^{-1}\right)$ & 9670 & 8708 & $<0.001$ \\
\hline (kcal day ${ }^{-1}$ ) & 2313 & 2083 & $<0.001$ \\
\hline Weight (kg) & 26.9 & 26.7 & 0.54 \\
\hline Height $(\mathrm{cm})$ & 125.4 & 125.4 & 0.97 \\
\hline BMI $\left(\mathrm{kg} \mathrm{m}^{-2}\right)$ & 17.0 & 17.0 & 0.79 \\
\hline Overweight (\%) & 21.3 & 18.5 & 0.24 \\
\hline Obesity (\%) & 13.4 & 11.6 & 0.24 \\
\hline DVI & 42.9 & 41.8 & 0.01 \\
\hline $\mathrm{HEI}^{*}$ & 56.4 & 53.9 & $<0.001$ \\
\hline
\end{tabular}

BMI - body mass index; DVI - Dietary Variety Index; HEI - Healthy Eating Index.

*The HEl does not consider relative scores for total cholesterol and total and saturated fat intake. 
of dairy products ( $470.8 \mathrm{ml}$ vs. $666.7 \mathrm{ml} ; P<0.001$ ). The UL children had lower intakes of meat products $(P<0.001)$, sausages $(P<0.001)$, fish $(P<0.001)$, vegetables $(P<0.001)$, fruits $(P<0.001)$, cereals $(P<0.001)$, olive oil $(P<0.001)$ and carbonated beverages $(P=0.14)$. The most important differences were observed for vegetables (294.4 $\mathrm{g}$ in the UL group vs. $459.3 \mathrm{~g}$ in the LL group) and fruits (292.7 g vs. $423.4 \mathrm{~g}$ ) (Table 2).

From Table 3 we can see that the nutritional profile of the LL children was closer to nutritional guidelines than that of the UL children. The ratio unsaturated fatty acids/ SFA and intakes of carbohydrates and fibre were higher in LL group children than in those from the UL group. UL group children showed higher intakes of lipids, proteins and cholesterol $(P<0.001$ in all cases). Although vitamin $\mathrm{A}$ intake and calcium intake were lower in the children from the LL group, mean values in this group (1429.7 mg and $644.8 \mu \mathrm{g}$ ) were higher than the recommended intake by $61.2 \%$ and $78.7 \%$, respectively. The intakes of potassium and of the other vitamins studied $\left(C, D, B_{6}\right.$, $\mathrm{E}$ and folic acid) were higher in children from the LL group, and their mean level in this group was higher than the recommended intake in all cases except vitamin $\mathrm{B}_{6}$.

As can be seen from Table 4, children from the LL group showed slightly higher HDL-C $(P=0.09)$ and apolipoprotein A1 (apoA1) $(P=0.05)$ levels and lower LDL-C levels $(P=0.04)$. The ratio LDL-C/HDL-C was lower $(P=0.04)$ in the LL group, as was the ratio apoB/apoA1 $(P=0.04)$.

\section{Discussion}

The children with a lower saturated fat intake had a superior quality of diet as assessed according to its variety and the HEI. Compared with the UL children, the LL children showed a higher consumption of fruits and vegetables, legumes, meat, fish and olive oil and a lower consumption of dairy products. From a nutritional point of view, the LL children showed a lower consumption of fat, proteins and cholesterol and higher intakes of carbohydrates and fibre. While vitamin A and calcium intakes were lower in the LL children, the intakes of potassium and the other vitamins studied $\left(\mathrm{C}, \mathrm{D}, \mathrm{B}_{6}, \mathrm{E}\right.$ and folic acid) were higher in this group. The plasma indicators for cardiovascular risk, specifically LDL-C/HDL-C and apoB/apoA1, were slightly lower in LL children than in UL children.

Energy intake was clearly higher in LL children, in contrast with the results of other studies ${ }^{9,35,36}$. There were no differences between the two groups in height, weight or BMI, which is consistent with the results of most other studies $^{8,9,16,17}$. In spite of this, the higher percentage of overweight and obese children in the LL group may be due to their higher energy intake. Epidemiological evidence about the relationship between fat intake and obesity is highly inconsistent ${ }^{37}$. Therefore, it is surprising that the decrease in the percentage of energy from fat found in children in the USA between 1987 and 1995 was accompanied by a fat intake that remained the same or increased slightly and by increases in total energy intake and the prevalence of obesity ${ }^{38}$. These results seem to indicate that the important factors are the absence of regular physical activity combined with excessive energy intake, whether or not this energy comes from fat or carbohydrates $^{37}$.

The LL children had an HEI score that was 2.5 points higher than that of the UL children. This is comparable to the results of a study with 5- to 7-year-old American girls divided in two groups according to whether or not their

Table 2 Food intake* relative to percentage of energy provided by saturated fatty acids (SFA)

\begin{tabular}{|c|c|c|c|}
\hline & \multicolumn{2}{|c|}{ SFA intake } & \multirow[b]{2}{*}{$P$-value } \\
\hline & Lower $(\leq 14.5)$ & Upper $(>14.5)$ & \\
\hline Dairy products & $470.8(446.8-494.8) \dagger$ & 666.7 (649.7-683.7) & $<0.001$ \\
\hline Eggs & $17.2(16.1-18.3)$ & $18.5(17.8-19.2)$ & 0.20 \\
\hline Meat & 104.7 (99.6-109.8) & $93.7(91.1-96.4)$ & $<0.001$ \\
\hline Poultry & $25.5(23.8-27.3)$ & $24.6(23.7-25.4)$ & 0.33 \\
\hline Sausages & $41.9(38.4-45.6)$ & $34.6(33.3-36)$ & $<0.001$ \\
\hline Fish & $51.5(44.0-59.1)$ & $41.5(39.9-43)$ & $<0.001$ \\
\hline Blue fish & 19.8 (17.6-21.9) & $17.3(16.4-18.2)$ & 0.04 \\
\hline Vegetables & $459.3(419.7-499)$ & 294.4 (283.2-305.6) & $<0.001$ \\
\hline Fruits & $423.4(389.1-457.7)$ & 292.7 (281.0-304.4) & $<0.001$ \\
\hline Legumes & $22.9(15.6-30.4)$ & $16.6(15.8-17.5)$ & 0.11 \\
\hline Cereals & $158.3(148.7-167.8)$ & $136.0(132.0-140.0)$ & $<0.001$ \\
\hline Olive oil & $24.6(23.7-25.6)$ & $19.9(19.2-20.6)$ & $<0.001$ \\
\hline Baked goods & $57.4(50.5-64.3)$ & $60.6(56.7-64.4)$ & 0.43 \\
\hline Added salt & $1.98(1.84-2.12)$ & $1.94(1.87-2.01)$ & 0.62 \\
\hline Carbonated beverages & $51(36.1-65.9)$ & $45(39.9-50.2)$ & 0.14 \\
\hline Natural juices & $96(79.3-112.7)$ & 94.3 (87.4-101.3) & 0.83 \\
\hline
\end{tabular}


Table 3 Nutritional intake relative to percentage of energy provided by saturated fatty acids (SFA)

\begin{tabular}{|c|c|c|c|c|}
\hline & \multirow[b]{2}{*}{ Recommendation } & \multicolumn{2}{|c|}{ SFA intake } & \multirow[b]{2}{*}{$P$-value } \\
\hline & & Lower ( $\leq 14.5)$ & Upper (>14.5) & \\
\hline SFA & $\leq 10 \%$ & $13.2(13.1-13.4)^{\star}$ & $17.6(17.4-17.7)$ & $<0.001$ \\
\hline MUFA & $15-20 \%$ & $17.3(17-17.7)$ & $18.5(18.4-18.7)$ & $<0.001$ \\
\hline PUFA & $\leq 8 \%$ & $8.4(8.2-8.6)$ & $8.3(8.2-8.4)$ & 0.27 \\
\hline Fats & $\leq 35 \%$ & $43.4(42.8-43.9)$ & $46.6(46.3-46.9)$ & $<0.001$ \\
\hline UFA/SFA & $\geq 2$ & $1.95(1.91-1.99)$ & $1.55(1.53-1.56)$ & $<0.001$ \\
\hline Cholesterol & $<200$ mg day $^{-1}$ & $322.1(304.2-340)$ & $364.9(356.2-373.6)$ & $<0.001$ \\
\hline Carbohydrates & $55-60 \%$ & $42.5(41.8-43.2)$ & $37.2(36.8-37.6)$ & $<0.001$ \\
\hline Protein & $10-13 \%$ & $15.9(15.6-16.2)$ & $17.5(17.4-17.7)$ & $<0.001$ \\
\hline Fibre & $11-17$ g day $^{-1}$ & $24.8(23.6-26)$ & $18.5(18.0-18.9)$ & $<0.001$ \\
\hline Potassium & mg day $^{-1}$ & $3602(3447-3756)$ & $3004(2950-3057)$ & $<0.001$ \\
\hline Calcium & $800 \mathrm{mg} \mathrm{day}^{-1}$ & $1430(1355-1504)$ & $1612(1573-1651)$ & $<0.001$ \\
\hline Sodium & $<2400 \mathrm{mg}$ day $^{-1}$ & 2734 (2581-2879) & 2733 (2671-2794) & 0.40 \\
\hline Vitamin C & $55 \mathrm{mg} \mathrm{day}^{-1}$ & $241.7(226.3-257)$ & $187(182.1-191.9)$ & $<0.001$ \\
\hline Vitamin $\mathrm{B}_{6}$ & $1.4 \mathrm{mg} \mathrm{day}^{-1}$ & $1.26(1.20-1.32)$ & $1.04(1.01-1.06)$ & $<0.001$ \\
\hline Folic acid & $100 \mu \mathrm{g}$ ay $^{-1}$ & $238.8(226.6-251.1)$ & $199.7(196.4-203.1)$ & $<0.001$ \\
\hline Vitamin E & 8 mg day $^{-1}$ & $12.6(11.9-13.3)$ & $10.5(10.3-10.7)$ & $<0.001$ \\
\hline Vitamin A & $400 \mu \mathrm{g}_{\text {day }^{-1}}$ & $644.8(618.3-671.2)$ & $668.7(656.4-681.1)$ & 0.09 \\
\hline Vitamin D & $5 \mu \mathrm{g} \mathrm{day}^{-1}$ & $5.41(5.13-5.69)$ & $5.14(4.98-5.29)$ & 0.11 \\
\hline
\end{tabular}

MUFA - monounsaturated fatty acids; PUFA - polyunsaturated fatty acids; UFA - unsaturated fatty acids.

${ }^{*}$ Values in parentheses are $95 \%$ confidence intervals.

total fat intake exceeded $30 \%$ of their total energy intake, although the magnitude of the difference ( 1.5 points) and the global HEI score were lower in the American study ${ }^{36}$. In both studies, and in a study carried out with a sample of children in Madrid aged 2 to 6 years ${ }^{9}$, intakes of vitamins $\mathrm{B}_{6}, \mathrm{C}$ and folic acid were higher in LL children. In the case of the American girls vitamin A intake was also higher in the LL group. However, in both the Madrid study and our own, vitamin A intake was lower in LL children. This difference could be due to the fact that, while dairy product intakes were similar for both groups in the American study, in the two Spanish studies it was found to be much lower in the LL group. Even so, the average vitamin A intake in both cases was well above the minimum recommended. These observations are consistent with the fact that, except for dairy products, the LL children have higher intakes of almost all food groups, particularly fruits and vegetables, as has been previously observed $^{9,39}$.
While intervention studies are fairly consistent with these results, perhaps because of the strict supervision of their subjects, observational studies are not. In a nutritional educational study carried out with 4- to 10year-old-children, the children who most reduced their fat intake had lower intakes of vitamins $\mathrm{D}$ and $\mathrm{E}$ and lower consumption of dairy products, fatty foods and oils ${ }^{40}$. In our study, as in the Madrid study ${ }^{9}$, the intakes of vitamins $\mathrm{D}$ and $\mathrm{E}$ were higher in the LL children. Although the LL children consumed fewer dairy products, these differences could be explained because the consumption of blue fish and olive oil - foods rich in vitamin D and E, respectively - was higher in this group. Likewise, a British study including 18- to 43-month-old children did not observe differences in vitamin $\mathrm{D}$ and $\mathrm{E}$ intakes according to the percentage of energy intake from fat ${ }^{41}$. In this case, children from the lowest quartile of fat intake showed a similar consumption of oils and a higher consumption of fish than the rest. In the Bogalusa Study, the percentage of

Table 4 Plasma lipid concentrations relative to percentage of energy provided by saturated fatty acids (SFA)

\begin{tabular}{|c|c|c|c|}
\hline & \multicolumn{2}{|c|}{ SFA intake } & \multirow[b]{2}{*}{$P$-value } \\
\hline & Lower ( $\leq 14.5)$ & Upper (>14.5) & \\
\hline Cholesterol (mg dl $\left.{ }^{-1}\right)$ & $180.9(176-185.9)^{*}$ & $183.5(181.3-185.7)$ & 0.16 \\
\hline HDL-C $\left(\mathrm{mg} \mathrm{dl}^{-1}\right)$ & $60.5(58.1-62.9)$ & $58.4(57.4-59.5)$ & 0.09 \\
\hline LDL-C $\left(\mathrm{mg} \mathrm{dl}^{-1}\right)^{\prime}$ & 105.8 (102.2-109.3) & $110.6(109.3-111.8)$ & 0.04 \\
\hline LDL-C/HDL-C & $1.87(1.78-1.96)$ & $2.02(1.96-2.09)$ & 0.04 \\
\hline Triglycerides $\left(\mathrm{mg} \mathrm{dl}^{-1}\right)$ & $74.5(70.4-78.6)$ & $72.9(71.0-74.8)$ & 0.46 \\
\hline ApoA1 $\left(\mathrm{mg} \mathrm{dl}^{-1}\right)$ & $137.6(134.4-140.7)$ & $134.1(132.6-135.6)$ & 0.05 \\
\hline ApoB $\left(\mathrm{mg} \mathrm{dl}^{-1}\right)^{\prime}$ & $70.7(68.1-73.4)$ & $71.2(70.0-72.4)$ & 0.40 \\
\hline ApoB/apoA1 & $0.52(0.50-0.53)$ & $0.54(0.53-0.55)$ & 0.04 \\
\hline Glucose $\left(\mathrm{mg} \mathrm{dl}^{-1}\right)$ & $91.3(89.3-93.3)$ & $90.2(89.5-90.9)$ & 0.89 \\
\hline
\end{tabular}

HDL-C - high-density lipoprotein cholesterol; LDL-C - low-density lipoprotein cholesterol; apoA1 - apolipoprotein A1; apoB - apolipoprotein B.

${ }^{\star}$ Values in parentheses are $95 \%$ confidence intervals. 
children who did not reach the minimum recommended intake of vitamins $\mathrm{B}_{6}, \mathrm{~B}_{12}$ and $\mathrm{E}$, thiamine, riboflavin and niacin was significantly higher among children with a fat intake lower than $30 \%$ of total intake ${ }^{35}$. On the other hand, in a study carried out in Oslo with 8- to 12-year-old children, those for whom less than $30 \%$ of energy intake was from fat showed higher nutritional density of thiamine, niacin, folic acid and vitamin $C^{39}$. For children in the LL group of our study, total fat intake was $43.4 \%$ of the total energy intake. Thus we do not know if the nutritional profile observed will be maintained with intakes below 30\%.

The lower intakes of dairy products and calcium in the LL children were consistent with those observed in other studies $9,35,40,42$. Although calcium intake in LL children was well above the recommended intake, we do not know if this would be same if they followed a diet with a lower content in saturated fat. Besides, whole milk was the most important source of SFA for the children in our study $\left(14.9 \%\right.$ of SFA intake) ${ }^{43}$. Consequently, a prudent and effective strategy to reduce saturated fat intake would be the substitution of whole dairy products with skimmed milk products ${ }^{44}$. This approach has shown its efficacy in the US child population and could easily be applied in Spain, where the consumption of low-fat dairy products among children is very low ${ }^{21}$.

Even though some observational studies do not find any association between fatty acid intake and plasma cholesterol levels in children ${ }^{7}$, others observe that this relationship follows the same patterns as in adults 6,8 . These observations have been confirmed by several interventional studies carried out in children, which show that the reduction of total or saturated fat intake induces a decrease in plasma cholesterol levels, particularly LDL-C ${ }^{45,46}$. In the only clinical trial in which differences in plasma cholesterol levels between groups were not observed, the intervention produced a very small reduction in total fat in the intervention group compared with the control group, and this reduction affected all fat components (saturated and unsaturated) equally ${ }^{15}$. Besides, the changes observed in plasma cholesterol levels in Spanish children over the last few years coincide with the expected theoretical values according to the observed tendencies in fatty acid intake ${ }^{47}$. Our results were as expected, with statically significant differences for LDL-C, LDL-C/HDL-C and apoB/apoA1, indicators considered among the best markers of cardiovascular risk in adults. These observations contrast with the results of a study carried out in Spanish children in Madrid' ; however, children in that study were around 4 years old and the method for the evaluation of diet was different. However, the STRIP study (The Special Turku Coronary Risk Factor Intervention Project), with an intervention conducted to reduce fat intake and cholesterol, achieved reductions of between 3 and 5\% for total cholesterol and LDL-C levels maintained for between 7 months and 5 years ${ }^{46}$.
In conclusion, the growth rate of children does not seem to be affected by the level of saturated fat intake. Furthermore, in the ranges of intake observed in this study, diets with less saturated fat were associated with better alimentary, nutritional and plasma lipid profiles. However, considering the high intake of saturated fat in the population studied, it would be necessary to replicate this study on children with lower saturated fat intakes to ensure that the benefits observed are maintained when the recommended SFA intake levels are achieved.

\section{Acknowledgements}

This study was partly funded by grants from the Fondo de Investigación Sanitaria (FIS 020994, FIS02/3104) and the Ministerio Agricultura Pesca y Alimentación. We thank Alexander G Borun for manuscript revision.

\section{References}

1 Hu FB, Manson JE, Willett WC. Types of dietary fat and risk of coronary heart disease: a critical review. Journal of the American College of Cardiology 2001; 20: 5-19.

2 World Health Organization (WHO). Diet, Nutrition, and the Prevention of Chronic Diseases. Report of a Joint Food and Agriculture Organization/WHO Expert Consultation. WHO Technical Report Series No. 916. Geneva: WHO, 2003.

3 Trumbo P, Schlicker S, Yates AA, Poos M. Dietary reference intakes for energy, carbohydrate, fiber, fat, fatty acids, cholesterol, protein and amino acids. Journal of the American Dietetic Association 2002; 102: 1621-30.

4 Krauss RM, Eckel RH, Howard B, Appel LJ, Daniels SR, Deckelbaum RJ, et al. Revision 2000: a statement for healthcare professionals from the nutrition committee of the American Heart Association. Circulation 2000; 102: 2284-99.

5 Serra Ll, Aranceta J. Objetivos Nutricionales para la población española. Consenso de la Sociedad Española de Nutrición Comunitaria. In: Serra Ll, Aranceta J, Mataix J, eds. Guías Alimentarias para la Población Española. Recomendaciones para una Dieta Saludable. Madrid: IM\&C, 2001; 345-51.

6 Nicklas TA, Dwyer JH, Feldman HA, Luepker R, Kelder SH, Nader PR. Serum cholesterol levels in children are associated with dietary fat and fatty acid intake. Journal of the American Dietetic Association 2002; 102: 511-7.

$7 \mathrm{Ku}$ CY, Gower BA, Nagy TR, Goran MI. Relationships between dietary fat, body fat, and serum lipid profile in prepubertal children. Obesity Research 1998; 6: 400-7.

8 Rogers I, Emmet P. Fat content of the diet among preschool children in southwest Britain: II. Relationship with growth, blood lipids, and iron status. Pediatrics 2001; 108: e49.

9 Ortega R, Requejo A, Navia B, López-Sobaler A, Andrés P, Perea JM, et al. Effect of saturated fatty acid consumption on energy and nutrient intake and blood lipid levels in preschool children. Annals of Nutrition \& Metabolism 2001; 45: 121-7.

10 American Academy of Pediatrics. Cholesterol in childhood. Pediatrics 1998; 101: 141-7.

11 Lifshitz F, Tarim O. Considerations about dietary fat restrictions for children. Journal of Nutrition 1996; 126 1031S-41S.

12 Zlotkin SH. A review of the Canadian 'Nutrition recommendations update: dietary fat and children'. Journal of Nutrition 1996; 126: 1022S-7S 
13 Olson RE. Is it wise to restrict fat in the diets of children? Journal of the American Dietetic Association 2003; 100: $28-32$.

14 Kavey R, Daniels SR, Lauer R, Atkins DL, Hayman L, Taubert K. American Heart Association guidelines for primary prevention of atherosclerotic cardiovascular disease beginning in childhood. Circulation 2003; 107: 1562-6.

15 Luepker R, Perry C, McKinlay S, Nader PR, Parcel G, Stone E, et al. Outcomes of a field trial to improve children's dietary patterns and physical activity. The Child and Adolescent Trial for Cardiovascular Health (CATCH). Journal of the American Medical Association 1996; 275: 768-76.

16 Lapinleimu H, Viikari J, Jokinen E, Salo P, Routi T, Leino A, et al. Prospective randomised trial in 1062 infants of diet low in saturated fat and cholesterol. Lancet 1995; 345: 471-6.

17 Lagström H, Seppänen R, Jokinen E, Niinikoski H, Ronemaa $\mathrm{T}$, Viikari J, et al. Influence of dietary fat on the nutrient intake and growth of children from 1 to $5 \mathrm{y}$ of age: the Special Turku Coronary Risk Factor Intervention Project. American Journal of Clinical Nutrition 1999; 69: 516-23.

18 Lifshitz F, Moses N. Growth failure. A complication of dietary treatment of hypercholesterolemia. American Journal of Diseases of Children 1989; 143: 537-42.

19 Picciano M, Smiciklas-Wright H, Birch L, Mitchell D, MurrayKolb L, McConahy K. Nutritional guidance is needed during dietary transition in early childhood. Pediatrics 2000; 106: 109-14.

20 Rodríguez-Artalejo F, Garcés C, Gil A, Lasunción MA, MartínMoreno JM, Gorgojo L, et al. Estudio Cuatro Provincias: principales objetivos y diseño. Revista Espanola de Cardiologia 1999; 52: 319-26.

21 Rodríguez-Artalejo F, Garcés C, Gorgojo L, López E, MartínMoreno JM, Benavente M, et al. Dietary patterns among children aged 6-7 years in four Spanish cities with widely differing cardiovascular mortality. European Journal of Clinical Nutrition 2002; 56: 1-8.

22 REAL DECRETO 561/1993, de 16 de abril, por el que se establecen los requisitos para la realización de ensayos clínicos con medicamentos. Boletín Oficial del Estado No. 114, 13 May 1993; 14346-64.

23 Martín-Moreno JM, Boyle P, Gorgojo L, Maisonneuve P, Fernandez-Rodriguez JC, Salvini S, et al. Development and validation of a food frequency questionnaire in Spain. International Journal of Epidemiology 1993; 22: 512-9.

24 Gorgojo L, Guallar E, Martín-Moreno JM, López-Nomdedeu $\mathrm{C}$, Vázquez C, Martí-Henneberg C, et al. Encuestas alimentarias en los niños españoles de edad escolar: análisis del período 1984-1994. Medicina Clinica 1999; 112: 368-74.

25 Moreiras-Varela O, Carbajal A, Cabrera L. Tablas de Composición de Alimentos. Madrid: Ediciones Pirámide, 2001.

26 Mataix J, Mañas M, Llopis J, Martínez E, Sánchez J, Borregón A. Tabla de Composición de Alimentos Españoles. Granada: Editorial Universidad de Granada, 1998.

27 Cole TJ, Bellizi MC, Flegal KM, Dietz WH. Establishing a standard definition for child overweight and obesity worldwide: international survey. British Medical Journal 2000; 320: 1240-3.

28 McCullough ML, Feskanich D, Rimm EB, Giovannucci EL, Ascherio A, Variyam JM, et al. Adherence to the Dietary Guidelines for Americans and risk of major chronic disease in men. American Journal of Clinical Nutrition 2000; 72 : $1223-31$.

29 US Department of Agriculture (USDA). The Healthy Eating Index. Washington, DC: USDA, 1995.
30 Kennedy ET, Ohls J, Carlson S, Fleming K. The Healthy Eating Index: design and applications. Journal of the American Dietetic Association 1995; 95: 1103-8.

31 US Department of Agriculture and US Department of Health and Human Services. Nutrition and Your Health: Dietary Guidelines for Americans. Home and Garden Bulletin No. 232. Washington, DC: US Government Printing Office, 2000; $1-39$.

32 McCullough ML, Feskanich D, Stampfer MJ, Rosner BA, Hu FB, Hunter DJ, et al. Adherence to the Dietary Guidelines for Americans and risk of major chronic disease in women. American Journal of Clinical Nutrition 2000; 72: 1214-22.

33 Martín-Moreno JM. Adjustment for total caloric intake in nutritional studies: an epidemiologic perspective. European Journal of Clinical Nutrition 1993; 47: S51-2.

34 Cody RP, Smith JK. Applied Statistics and the SAS Programming Language. Englewood Cliffs, NJ: PrenticeHall, 1991.

35 Nicklas TA, Webber LS, Koschak M, Berenson GS. Nutrient adequacy of low fat intakes for children: the Bogalusa Heart Study. Pediatrics 1992; 89: 221-8.

36 Lee Y, Mitchell D, Smiciklas-Wright H, Birch L. Diet quality, nutrient intake, weight status, and feeding environments of girls meeting or exceeding recommendations for total dietary fat of the American Academy of Pediatrics. Pediatrics 2001; 107: e95.

37 Willett WC. Dietary fat plays a major role in obesity: no. Obesity Research 2002; 3: 59-68.

38 Johnson RK. Changing eating and physical activity patterns of US children. Proceedings of the Nutrition Society 2000; 59: $295-301$.

39 Tonstad S, Sivertsen M. Relation between dietary fat and energy and micronutrient intakes. Archives of Disease in Childhood 1997; 76: 416-20.

40 Dixon L, McKenzie J, Shannon B, Mitchell D, SmiciklasWright $\mathrm{H}$, Tershakovec A. The effect of changes in dietary fat on the food group and nutrient intake of 4- to 10-year-oldchildren. Pediatrics 1997; 100: 863-72.

41 Rogers I, Emmet P. Fat content of the diet among pre-school children in Britain; relationship with food and nutrient intakes. European Journal of Clinical Nutrition 2002; 56: 252-63.

42 Shea S, Basch CE, Stein AD, Contento IR, Irigoyen M, Zybert $\mathrm{P}$. Is there a relationship between dietary fat and stature or growth in children three to five years of age? Pediatrics 1993; 92: 579-86.

43 Royo-Bordonada MA, Gorgojo L, de Oya M, Garcés C, Rodríguez-Artalejo F, Rubio R, et al. Food sources of nutrients in the diet of Spanish children: the Four Provinces Study. British Journal of Nutrition 2003; 89: 105-14.

44 Peterson S, Sigman-Grant M. Impact of adopting lower-fat food choices on nutrient intake of American children. Pediatrics 1997; 100: e4.

45 Obarzanek E, Kimn S, Barton B, Horn L, Kwiterovich P, Simons-Morton D, et al. Long-term safety and efficacy of a cholesterol-lowering diet in children with elevated lowdensity lipoprotein cholesterol: seven-year results of the Dietary Intervention Study in Children (DISC). Pediatrics 2001; 107: 256-64.

46 Jokinen E, Rask-Nissilä L, Jokinen E, Terho P, Tammi A, Lapinleimu H, et al. Neurological development of 5-year-old children receiving a low-saturated fat, low-cholesterol diet since infancy. A randomized controlled trial. Journal of the American Medical Association 2000; 284: 993-1000.

47 Couch S, Cross A, Kida K, Ros E, Plaza I, Shea S, et al. Rapid Westernization of children's blood cholesterol in 3 countries: evidence for nutrient-gene interactions? American Journal of Clinical Nutrition 2000; 72: 1266S-74S. 